\title{
Academic Procrastination in Mathematics: Causes, Dangers and Implications of Counselling for Effective Learning
}

\author{
Asikhia, Olubusayo. A. (Mrs.) \\ Senior Lecturer in the School of Education \\ Michael Otedola College of Primary Education \\ P.M.B 1028 Noforija-Epe, Lagos, Nigeria \\ Tel: 234-070-3953-8804 E-mail: mbusay@yahoo.com
}

\begin{abstract}
This paper focused on causes and dangers of academic procrastination (a behavioural problem that involves delaying a task which needs to be accomplished) in mathematics and the need for counseling students who are procrastinators especially of mathematics. Thus, in order to have a comprehensive understanding of the topic, the meaning, causes and its debilitating effects on student's mathematics achievement were discussed after which the counsellor's role in helping students get out of this behavioural problem in order to ensure a sustainable educational system were discussed.
\end{abstract}

Keywords: Academic procrastination, Academic performance, Mathematics, Counselling

\section{Introduction}

Procrastination, which is a frequent failure at doing what ought to be done to reach one's goals is now a common phenomenon among students particularly those preparing for their final examination and this is doing more harm to their academic achievement than good. For instance, in a study carried out by Akinsola, Tella and Tella (2007) on 150 part 3 and 4 students from the department of mathematics and mathematics education of the University of Ibadan and University of Lagos, it was discovered that there is a significant correlation between academic procrastination and mathematics academic achievement. This implies that the more the subjects procrastinate, the more their achievement in mathematics decreased. The study carried out by Besinck, Rothblum and Mann (1986) also found out that procrastination was correlated with low self-esteem and anxiety in high school students. Tice and Bauneister (1997) also reported that students who have strong tendencies to procrastinate tend to have low examination grades than non-procrastinators. Also, the report by Beck, Koons and Migram (2000) Tuckman, Abry and Smith (2000) and Popoola (2005) show that procrastination is associated with poor academic achievement. According to Sirois and Pychy (2002), most students who suffer from procrastination resist completing assignments and addressing other deadlines that evoke tension and anxiety.

Although, the optimal goal of schooling is that students develop an indepth understanding of various content domains as well as possess high expectations for success, this seems to be an illusion as many students do not take their study serious until very close to examination period. This is especially true of mathematics which is a subject that demands students' understanding of mathematical reasoning and develop their mathematical knowledge through problem solving.

Mathematics is a broad domain addressing the measurement, properties and relations of quantities as expressed in numbers or symbols (Lynn 2006) and as opined by Akinsola and Tella (2003) it is an important school subject because it is associated with more academic and/or career opportunities. However, relatively little is known about mathematical cognition because most students do not give in the needed attention and time. Meanwhile, admission into tertiary institution of learning depends on very good academic performance in mathematics and English.

Moreover, education at secondary level is supposed to be the bedrock and the foundation towards higher knowledge in tertiary institutions. It is an investment as well as an instrument that can be used to achieve a more rapid economic, social, political technological, scientific and cultural development in the country. But on the contrary, there is a consensus of opinion about poor performance in especially the two core subjects - English and Mathematics. (Agwah 2003).

Mathematics is a very important subject in secondary school education because it is one of the compulsory subject and a mandatory requirement for admission. Burton, cited in Agwah and Usman (2003) relates the importance of mathematics to the scientific, industrial, technology and social progress of any society. That mathematics is an important subject is indubitable but it is very sad to note that the performance by secondary school students especially at WAEC and GCE results in the subject in recent times is not encouraging. This can 
be attributed to the fact that majority of secondary school students has been observed to be procrastinators and basically because not much has been done to counsel them otherwise.

Sutton (1997) argues that mathematics by its nature involves both cognition and affective effects and the glory of mathematics lies in the fact that mathematics does not come easily to anyone. It is in the struggle to understand and the manner in which this is met that one gets equipped in the knowledge of mathematics. However, most students often dislike mathematics as a subject. This is supported by Hopper (2005) and Phillips (2000) who discovered that mathematics to some students is often associated with pain and frustration and this may account for the reason why they procrastinate in studying mathematics. This assertion is also supported by Solomon and Rothblum (1984) who posit that people tend to avoid tasks which they find unpleasant and engage in activities which are more rewarding especially with short-term over long term gains. Also, Akinsola, Tella and Tella (2007) observe that many students refer to mathematics as being difficult and as asserted by the learning common fact series, procrastination often results when a task seems difficult, unpleasant or overpowering. This is especially true of adolescents who often prefer pleasurable times to being constrained to do something.

A developed and sustainable educational system is an enviable longing in any nation but this will continue to be an illusion if nothing seriously is done to help our unguided students by taking counseling especially on core subjects like mathematics very seriously in our secondary schools. If our secondary school students especially those in the senior secondary school continue to procrastinate, definitely, the weak manifestation of academic achievement in the subject will continue.

This is why this paper is a timely one to:

- Explain the meaning of procrastination

- Discuss the causes of procrastination

- Emphasize the dangers of procrastination on students especially those preparing for their senior secondary school certificate examinations and

- $\quad$ Point out possible ways of remediating the behaviour (procrastination) for improved academic achievement in mathematics.

\section{Conceptual framework on procrastination}

This section deals with the meaning of procrastination, characteristics and types of procrastinators.

\subsection{Meaning of Procrastination}

According to Lay (1986) procrastination is a frequent failure at doing what ought to be done to reach goals. In other words, procrastination as a behaviour becomes obvious when someone continues to fail in doing what he or she ought to do to achieve certain desirable goals. Oweini and Harray (1993) also define procrastination as the acts of needlessly delaying a task until the point of some discomfort. The issue of delaying what out to be done to later times is the bone of contention on the concept of procrastination and as pointed out by Janse and Carton 1999 , procrastination is a behavioural problem that many adults experience on a daily basis. If procrastination as opined by Jansen and Canton (1999) is a behavioural problem that even adults engage in, then it becomes a more serious problem for students in the secondary school (who are mostly adolescents).

Still on the discourse of procrastination, Noran (2000) defines procrastination as avoiding doing a task which needs to be accomplished. In other words, most people who procrastinate would rather spend time socializing with friends or relatives rather than working on an important work that ought to be done soon or one would rather be watching an exciting movie on the television rather than studying for an upcoming test or examination.

Also, Popoola (2005) defines procrastination as a dispositional trait which has cognitive, behavioural and emotional components. According to him, this dispositional trait makes an individual postpone doing things that make him or her anxious and apprehensive. This description of procrastination shows that it is a natural behaviour that can be exhibited by anyone and that such a natural tendency needs to be reduced to the minimal.

\subsection{Characteristics of procrastinators}

There are certain things that characterize individuals who procrastinate. Some of these are low self esteem, self efficacy, self-critical behaviour, irrational fear of success or failure and the likes. Some of these are discussed below:

\subsubsection{Self Efficacy}

This refers to people's judgments of their capabilities to organize and execute courses of action required to attain designated types of performances (Bandura 1986). According to him, self efficacy strongly influences the choices people make, the effort they expend, and how long they persevere in the face of challenge. By 
implication, how people behave can often be better predicted by their beliefs about their capabilities than by what they are actually capable of accomplishing as these beliefs help determine what individuals do with the knowledge and skills they have. Some other researchers like Maddux, Norton and Stollenberg (1986) have also established that self-efficacy is a strong predictor of behaviour. Perrari and Emmons (1995) also found out that procrastinators have low self esteem and delay task completion because they believe they lack the ability to achieve a task successively.

\subsubsection{Self critical behaviour}

A procrastinator is also believed to be highly self critical because of high expectations he or she has for the completion of a particular task and what others will say about him/her. This often makes such an individual not to even get started at all. This view is supported by Effert and Ferran (1989) who demonstrate that procrastinators are publicly self-conscious and highly self-critical. They added that procrastinators have perfectionism expectations and are over-conscious. This is why Popoola (2005) describes the procrastinator as someone who knows what he wants to do in some sense, can do it, is trying to do it, yet doesn't do it.

\subsubsection{Fear of success or failure}

This is another character of procrastinators as most of them display irrational fear of success or failure which may lead them to avoid studying mathematics. Rothblum (1984) further asserts that procrastinators may be emotional, overwhelmed and anxious, having less need for cognitive complexity and are more likely to attribute success to external and unstable factors. Other characteristics of procrastinators according to Noran (2000) are that he knows what he wants to do, is equipped to perform the task, is trying and planning to perform the task, but does not complete the task or excessively delays performing the task, as he works on less important obligations rather than fulfilling the more important obligation or he may use his time wastefully in some minor activities.

\subsection{Types of Procrastinators}

The different characteristics of procrastinators highlighted above shows that there are different types of procrastinators. Some of these are:

\subsubsection{Implosive Procrastinator}

According to Ferran and Emmons (1994), these are procrastinators who fail to pick up cues from the environment because of the inability to delay gratification of pleasure, lacking self control, lacking motivation for achieving targeted goals and lacking energy or organizational abilities. Thus, this type of procrastination is often related to the problem of perceiving and estimating time.

\subsubsection{Perfectionist procrastinator}

This type of procrastinators keeps themselves ready to work but avoid the activity and according to Ellis and Knaus (1977), this type of procrastination has been found to result from cognitive distortions or faulty thinking. Such procrastinators are therefore over-conscious and they tend to fear success or failure which eventually leads to neurotic avoidance. They lack self-efficacy and self-esteem and are self-conscious and self-critical. Furthermore, Norman (2000) posits that academic procrastinators typically make four cognitive dimensions which promote and maintain their task avoidance. These are over estimation of time left to perform tasks; under-estimation of time required to complete tasks. Overestimation of future motivational states, mis-reliance on the necessity of emotional congruence to succeed at task and belief that working when not in the mood to work is sub-optional.

\section{Causes of Procrastination}

Some of the causes of procrastination like self esteem and self efficacy, fear of success or failure, have already been mentioned under the characteristics of procrastinators and the types of procrastinators. However, Noran (2007) gave some other important causes of procrastination.

\subsection{Lack of time management/}

Someone who procrastinates suggests he/she is unable to manage time wisely. It implies uncertainty of priorities, goals and objectives. There is also a feeling that overwhelms one when doing a certain task. Subsequently, one postpones doing academic assignment for a certain data, while focusing on unproductive activities.

\subsection{Inability to concentrate or having low levels of conscientiousness on one's work.}

This is another reason for procrastination. This may be due to distortions in the environment, such as noise, cluttered study desk or trying to do an assignment on a bed. 


\subsection{Fear and anxiety related to failure:}

A third of procrastinating is the fear and anxiety related to failure. A person in this category would spend more time worrying about forthcoming tests and projects rather than plan for it and completing them.

\subsection{Type of students' characteristics}

Valadez (2006) have identified three types of students, as the unconcerned students, target-oriented and passionate students. According to him, unconcerned students objective is that they just want to pass the class, look for easiest way, and are apathetic about studying. Such students exercise behaviours such as they do little studying or reading, look for help at the last minute, memorize information, reproducing statements from source text, sometimes cheat and goof in class. Indeed such students certainly do not take study seriously and may never pay attention to proper time management.

\subsection{Lack of confidence:}

A lack of confidence in one self according to (Plessis, 2006) will automatically keep one from those things which ordinarily one is capable of doing. Procrastination which is not a device for avoiding mundane things but on a higher level, is avoiding the big decisions and big actions then set in and prevent one from making real difference in one's life.

\section{Effects of procrastination}

Students who suffer from procrastination which is an avoidance coping behavior often have many problems with their academic performance. Some of the effects of procrastination on students are:

\subsection{Tension and anxiety.}

According to Trabant (2006), anxiety is a state of uneasiness and apprehension about future uncertainties and that anxiety suggests feelings of fear and apprehension, feelings of resentment and rage over this various form of manipulation cannot surface in the child. According to Britannica Concise Encyclopedia (2006) defines anxiety in psychology as a feeling of dread, fear or apprehension often with no clearly justification. Also, anxiety is seen typically as the product of subjective, internal emotional states rather than a response to a clear and actual danger and as such it is different from fear. Thus, anxiety can be viewed anxiety in relation to: (i) fear (ii) feeling of persistent and uncontrollable worry and nervousness (iii) it increases in tension and it is often accompanied by some physical and biochemical changes in the body (iv) it is a feeling that comes from within but that is manifested in outward actions. It can be seen as an emotional state caused by things man is incapable of doing and which if uncontrolled can be harmful to the individual. It was revealed by Akinsola, Tella and Tella (2007) that students who procrastinate resist completing assignment and other deadlines that create tension and anxiety. Also Effert and Ferrari (1989) demonstrate that procrastinators may also be emotional, overwhelmed and anxious, having less need for cognitive complexity and are more likely to attribute success to external and unstable factors (Solomon and Rothblum, 1984).

\subsection{Effect on students' academic performance}

Procrastination may also have debilitating effect on students' academic performance. This is supported by Tice and Baummeister (1997) who find out that procrastinator received significantly lower paper and examination grade than none procrastinators. Other research studies like Tuckman, Abry and Smith 2002; Beck, Koons and Morgan, 2000 and Wesley, 1994 confirmed this.

\section{Counselling Students with Procrastinating Attitude}

Since procrastination is not simply a habit, but complex pattern of recurring behaviours which includes emotions, thought, and actions and has comes habitual to the procrastinator, getting rid of it will involve replacing, circumventing or deactivating each one of the habits by new habits. Getting rid of such a behaviour may not be that easy because a simple decision could easily be overwhelmed by the force of habit and such a decision need to be implemented as a habit itself before it can compete effectively with the old habit. Thus, for a student to be able to confronts and control his procrastinating behaviour there will be need for counsellors to help students in the following ways:

\subsection{Critically examine themselves}

The first stage is for counsellors to help students to look at themselves critically and determine the distractive and incompetent attributes that negates their positive behaviours towards their academic activities.

\subsection{Instilling competence in students}

Procrastination as a form of incompetence has to be eliminated in order to cure it. Since incompetence is the opposite or lack of competence, the only way to eliminate it is to be replaced with competence (Wikibooks, 
2006). Personal competence is comprised of five elements: emotional strength, well-directed thoughts, time management skills, control over habits and task completion abilities (Wikibooks, 2006).

\subsection{Inculcating ability to be well organized}

Some of the practical steps that will make students to be well organized are for the students to be well organized by starting out small to accomplish the larger goal must be emphasized to them. In other words, a student may need to prepare a scale of daily preferences dividing major projects which seems overwhelming into little pieces. What is not done in one day can be added to the next day's list.

\subsection{Teaching students to start from simple to complex}

Also, a procrastinator may have to be taught to start with the easiest task and proceed from there to a more rigorous and demanding tasks. They must be made to see that success in the easier task is likely to motivate and ginger him to more difficult task and hence building up confidence in his ability to tackle academic matters. One of the major reasons why people avoid the very tasks that free them from mediocrity is their lack of self-confidence (Plessis, 2006).

\subsection{Instilling effective use of time in students}

When students manage time judiciously, taken time as precious commodity, periodically observing and modifying the use of it, procrastination may be reduced to the minimum. Such a student is likely to make sure that he/she is in the right class and have the proper prerequisites, and will be willing to review previous mathematics topics already forgotten which may be critical to the understanding of the new learning. In addition, student with low level of procrastination may also be taught to get involved in studying with classmate, teaching each other the principle involved and discussing difficult mathematics concept, and reading the textbooks for additional information and examples.

\section{Conclusion}

In conclusion, mathematics procrastination is very real and occurs among thousands of people. Much of this happens to students due to their hatred for mathematics. Today, the needs of society require a greater need for mathematics. Mathematics must be looked upon in a positive light to reduce academic procrastination in mathematics. Therefore, the role of counsellors in inculcating confidence, competence, effective use of time, good organization and the likes cannot be over-emphasized. Teachers must re-examine traditional teaching method which often do not match students' learning styles and skills needed in society. Lessons must be presented in a variety of ways. As a result once young children see mathematics as fun, they will enjoy it, and, the joy of mathematics could remain with them throughout the rest of their lives. In this way, developing a sustainable educational system will be ensured.

\section{References}

academics/trio/Math.pdf.

Agwah \& Usman (2002). Training of undergraduate teachers in Nigeria universities: focus on problems of effective integration and attitude of students to computers in mathematics instruction. [Online] Available: http.//www.math.uocgr/jetm2/proceeding/gap w9.pdf. (October18, 2007).

Akinsola, M. A. \& Tella, A. (2007). Correlates of academic procrastination and mathematics achievement of university undergraduate students. Eurasia Journal of Mathematics, Science and Technology Education, 3(4), 363-370.

Akinsola, M. K, and Tella A. (2003). Effectiveness of individualistic and cooperative teaching strategies in learning geometry and problem solving in mathematics among junior secondary, schools in Nigeria. Personality Study and Behaviour 23, 95-105.

Bandura, A. (1986). Social foundations of thoughts and action. Eaglewood Cliffs, NJ: Prentice Hall.

Beck, B. L. and Koons, S. R. \& Migram, D. L. (2000). Correlates and consequences of behavioural procrastinations: The effects of academic procrastination, self-consciousness, self-esteem, and self-handicapping. Journal of Social Behaviour and Persona.

Beswick, G. Rothblum, E. D. \& Mann, L. (1988). Psychological antecedents to student procrastination. Australian Psychologist. 23, 207.

Jansen, T \& Carton, J. S. (1999). The effect of locus of control and task difficulty on procrastination. Journal of Genetic Psychology, 160. 
Learning Common Fastfact Series (2004). Controlling procrastination. [Online] Available:http//.www.learningcommons.uoguelph.ca/fastfacts-procrastination. (October18, 2007).

Maddux, J. E. Norton, L. W. \& Stolenberg, C. D. (1986). Self-efficacy expectancy, outcome expectancy, and outcome value: Relative effects on behavioural intentions. Journal of Personality and Social Psychology, 51, 783-789.

Noran, F. Y. (2000). Procrastination among students in institutes of higher learning: challenges for K-Economy. [Online] Available: http://www.mahdzan.com/paper/procrastinate/Accessed on 17th Nov. 2006.

Oweini, A. \& Harray, N. (2005). The carrots or the sticks: What motivate students? A Manuscript. Lebanese American University. USA.

Plessis, D. (2006). Self confidence, fear and the inevitable procrastination. [Online] Available: http://www.selfimprovement-gym.com on $11^{\text {th }}$ Nov.2006.

Popoola, B. I. (2005). A study of the relationship between procrastinatory behaviour and academic performance of undergraduate students in a Nigerian University. African Symposium: An online Journal of Educational Research Network. [Online] Available: http.//www2.

Siegel, R. G. Galassi, J. P., \& Ware, W. B. (1985). A comparison of two models for predicting mathematics performance: Social learning versus mathematics aptitude-anxiety. Journal of Couselling Psychology, 32, 531-538.

Sirois, F.M. \& Pychyl, T.A (2002). Academic procrastination:Cost health and well-being. Presentation at APA convention, August 22, 2002, Chicago, Illinois. Slides available at http:/www.carleton.ca/ typcyl/prg/conferences/apa2002/apaslides2002/sld001.htm.

Tice, D.M, \& Baumeister, R.F. (1997).Longitudinal study ofprocrastination, performance, stress and health: Thecosts and benefits of dawdling. Psychological Science 18,454-458.

Tuckman, B.W.; Abry, D.A. \&Smith, D.R (2000).Learning and motivation strategies: Your guide to success. Upper Saddle River, N.J: Prentice-Hall.

Valdez. (2006). Math study skills: 12 steps to success in math.Retrieved November 10 http://www.rock.uwc.edu/. 